Vol 2. No. 1, Januari 2022 P-ISSN : 2774-8030, e-ISSN : 2774-8030

\title{
MEWUJUDKAN PUSTAKAWAN KEMENTERIAN KESEHATAN YANG KOMPETEN DAN PROFESIONAL MELALUI PEMILIHAN PUSTAKAWAN INOVATIF TERBAIK
}

\author{
RESTY KIANTINI \\ Pustakawan Kementerian Kesehatan \\ e-mail: resty_setiaji@yahoo.com
}

\begin{abstract}
ABSTRAK
Perpustakaan Kementerian Kesehatan merupakan perpustakaan pembina bagi perpustakaan dan pustakawan di lingkungan Kementerian Kesehatan yang tersebar di seluruh Indonesia. Keberhasilan perpustakaan sangat ditentukan oleh peran Pustakawan. Karena pustakawan merupakan profesi yang memiliki kontribusi besar dalam mewujudkan cita-cita luhur bangsa Indonesia dalam mencerdaskan kehidupan bangsa. Berdasarkan hal tersebut Perpustakaaan Kementerian Kesehatan menyelenggarakan Pemilihan Pustakawan Inovatif Terbaik. Metode yang digunakan dalam penulisan karya ilmiah ini adalah best practise. Best Practice adalah suatu ide atau langkah-langkah baru yang memberikan kontribusi luar biasa, berkesinambungan dan inovatif dalam memperbaiki pengembangan proses dan kualitas pendidikan. Best Practice perlu didiseminasikan kepada orang lain dengan berbagai strategi diberbagai tempat secara berulang-ulang sehingga dapat dicontoh dan diadopsi oleh orang lain. Pemilihan Pustakawan Inovatif Terbaik dilaksanakan melalui beberapa tahap. Diawali dari pembuatan TOR kegiatan, memasukkan butir kegiatan kedalam RKAKL, menentukan tema kegiatan, membuat pedoman, menyusun SK Kepanitiaan. Penilaian Pustakawan Inovatif Terbaik dilakukan dengan cara melihat kelengkapan dokumen, makalah inovasi dan presentasi. Yang mendapat nilai terbaik dari dewan juri akan ditetapkan sebagai Pustakawan Inovatif Terbaik di lingkungan Kementerian Kesehatan. Terpilih Pustakawan Inovatif Terbaik 1 sd 3 dan harapan 1 s/d 3. Pustakawan Inovatif Terbaik mendapatkan penghargaan dan hadiah di Malam Penghargaan Publikasi dan Pelayanan Publik Kementerian Kesehatan yang dihadiri oleh Menkes, MenpanRB dan Kepala Perpusnas. Pustakawan menjadi kunci utama keberlangsungan dan keberhasilan sebuah perpustakaan. Pemilihan Pustakawan Inovatif Terbaik dilaksanakan sebagai suatu bentuk apresiasi dan penghargaan kepada pustakawan di lingkungan Kementerian Kesehatan. Diharapkan dengan adanya kegiatan ini dapat memotivasi pustakawan di lingkungan Kementerian Kesehatan untuk terus berkarya, berinovasi, berkinerja dan berprestasi serta memiliki daya saing dengan profesi lainnya.
\end{abstract}

Kata Kunci: Pustakawan Terbaik, Pustakawan Inovatif, Kementerian Kesehatan, Perpustakaan

ABSTRACT

The Ministry of Health Library is a builder library for libraries and librarians within the Ministry of Health spread throughout Indonesia. The success of the library is largely determined by the role of the librarian. Because the librarian is a profession that has a major contribution in realizing the noble ideals of the Indonesian nation in the intellectual life of the nation. Based on this, the Ministry of Health Library held a Selection of the Best Innovative Librarian. The method used in writing this scientific paper is best practice. Best Practice is an idea or new steps that make an outstanding, sustainable and innovative contribution in improving the process development and quality of education. Best Practice needs to be disseminated to others with various strategies in various places repeatedly so that it can be imitated and adopted by others. The selection of the Best Innovative Librarian was carried out in several stages. Starting from making the TOR for activities, entering activity items into the RKAKL, determining the theme of the activity, making guidelines, compiling a Committee Decree. The Best Innovative Librarian Assessment is done by looking at the completeness of documents, innovation papers and presentations. The one who gets the best score from the jury will be designated as the Best Innovative Librarian within the Ministry of Health. The Best Innovative Librarian 1 to 3 and 
expectations 1 to 3 . The Best Innovative Librarian received awards and prizes at the Publication and Public Service Award Night of the Ministry of Health which was attended by the Minister of Health, Menpan-RB and the Head of the National Library. Librarians are the main key to the sustainability and success of a library. The selection of the Best Innovative Librarian was held as a form of appreciation and appreciation for librarians within the Ministry of Health. It is hoped that this activity can motivate librarians in the Ministry of Health to continue to work, innovate, perform and excel and have competitiveness with other professions.

Keywords: Best Librarian, Innovative Librarian, Ministry of Health, Library

\section{PENDAHULUAN}

Perpustakaan Kementerian Kesehatan merupakan perpustakaan khusus kementerian yang berada di bawah naungan Biro Komunikasi dan Pelayanan Masyarakat Sekretariat Jenderal. Perpustakaan ini telah ditetapkan sebagai perpustakaan yang telah terakreditasi A oleh Perpustakaan Nasional. Berdasarkan Peraturan Menteri Kesehatan (Permenkes) No. 58 Tahun 2015 tentang Pedoman Penyelenggaraan Perpustakaan di Lingkungan Kementerian Kesehatan pada pasal 4 (1) dikatakan bahwa Perpustakaan Kementerian Kesehatan memiliki tugas memberikan arah kebijakan dan pembinaan untuk perpustakaan di lingkungan Kementerian Kesehatan sesuai standar perpustakaan. Sebagai pembina, Perpustakaan Kementerian Kesehatan menaungi Perpustakan di lingkungan Kementerian Kesehatan yang terdiri dari Perpustakaan Unit Utama dan Perpustakaan Unit Pelaksana Teknis (UPT). Perpustakaan Unit Utama meliputi perpustakaan Direktorat Jenderal, Inspektorat Jenderal dan Badan. Sedangkan perpustakan UPT meliputi perpustakaan politeknik kesehatan, rumah sakit dan balai/loka. Total jumlah perpustakaan di lingkungan Kementerian Kesehatan sebanyak 242 perpustakaan dan 121 Pustakawan yang tersebar di seluruh Indonesia.

Sedangkan yang dimaksud dengan pustakawan menurut UU no. 43 Tahun 2007 adalah seseorang yang memiliki kompetensi yang diperoleh melalui pendidikan dan/atau pelatihan kepustakawanan serta mempunyai tugas dan tanggung jawab untuk melaksanakan pengelolaan dan pelayanan perpustakaan. Sudarsono (2020) mengatakan bahwa pada dasarnya sebuah perpustakaan adalah pustakawannya. Semua perubahan atau perkembangan sebuah perpustakaan selalu berawal dari diri pustakawannya. Selain itu Pustakawan juga merupakan profesi yang memiliki kontribusi besar dalam mewujudkan cita-cita luhur bangsa Indonesia dalam mencerdaskan kehidupan bangsa.

Berdasarkan hal tersebut Perpustakaan Kementerian Kesehatan sebagai unit pembina perpustakaan dan pustakawan di lingkungan Kementerian Kesehatan melaksanakan suatu kegiatan Pemilihan Pustakawan Inovatif Terbaik. Pemilihan Pustakawan Terbaik diselenggarakan sebagai bentuk apresiasi dan penghargaan kepada pustakawan di lingkungan Kementerian Kesehatan agar selalu berkarya, berinovasi, berprestasi, profesional dan memiliki kompetensi, menjadi contoh dan teladan bagi pustakawan lainnya. Adapun Pustakawan Inovatif adalah seorang pustakawan yang memiliki komitmen dan prestasi unggul dalam bidang kepustakawanan, berkepribadian menarik, profesional dan bertanggung jawab terhadap pelaksaaan tugasnya, sehingga pantas dijadikan panutan dan dapat memberi motivasi kepada para pustakawan dan tenaga perpustakaan di unit kerjanya (Kementerian Kesehatan, 2019).

Dikatakan oleh Fatmawati, E (2016) semakin beragamnya inovasi yang dimiliki oleh pustakawan maka akan menjadi semakin bagus dan kuat kedudukan pustakawan. Inovasi pustakawan muncul dari pemikiran individu yang kreatif yang timbul dari lingkungan SDM perpustakaan yang saling mendukung, kondusif sehingga menumbuhkan lahirnya sebuah inovasi. Nantinya pustakawan yang mendapat peringkat tertinggi berdasarkan hasil penilaian Dewan Juri Pemilihan akan ditetapkan sebagai Pustakawan Inovatif Terbaik di Lingkungan Kementerian Kesehatan dan disahkan dengan Keputusan Menteri Kesehatan RI. 


\section{METODE PELAKSANAAN}

Kegiatan ini dilakukan dengan menggunakan metode Best Practice. Pengertian Best Practice atau praktek terbaik dalam dunia pendidikan adalah suatu ide atau langkah-langkah baru yang memberikan kontribusi luar biasa, berkesinambungan dan inovatif dalam memperbaiki pengembangan proses dan kualitas pendidikan (Boven \& Morohashi, 2002). Sedangkan Best Practice menurut Panduan Desiminasi Best Practice adalah keberhasilan yang dialami dan diakui oleh pihak yang berkepentingan dalam melaksanakan tugas pendidikan. Ciri-ciri Best Practice itu sendiri meliputi tersedianya konsep yang akan dicapai, kendala yang ditemui, adanya upaya untuk mengatasi, kunci keberhasilan dan diakui serta layak disebarluaskan (Departemen Pendidikan Nasional, 2008)

Perpustakaan Kementerian Kesehatan sebagai pembina perpustakaan dan pustakawan di lingkungan Kementerian Kesehatan melaksanakan Pemilihan Pustakawan Inovatif Terbaik sebagai suatu upaya yang dilakukan dalam rangka meningkatkan kompetensi dan pengembangan profesionalisme Pustakawan di Lingkungan Kementerian Kesehatan.. Menurut Dastina, W dan Hikmat, N.A (2018) dengan adanya pembinaan pustakawan maka memberikan kesempatan kepada pustakawam untuk mempersiapkan diri mengembangkan karirnya. Karena keberhasilan perpustakaan sangat ditentukan oleh tersedianya tenaga pustakawan yang berdedikasi tinggi dan bekerja secara profesional. Selain itu pustakawan di lingkungan Kementerian Kesehatan dituntut untuk memberikan layanan prima dan berorientasi pada pemustaka (Kementerian Kesehatan, 2019). Sedangkan peningkatan kompetensi dan profesionalisme yang diperlukan oleh pustakawan yang bekerja di perpustakaan khusus dikatakan oleh Nashihuddin, W \& Aulianto, D.R. (2015) adalah untuk meningkatkan kemampuan pustakawan agar mampu berkompetisi, berdaya saing dan memberika kinerja yang optimal.

Pemilihan Pustakawan inovatif Terbaik merupakan suatu Best Practice karena melalui kegiatan ini dapat meningkatkan kinerja para pustakawan di lingkungan Kementerian Kesehatan dan juga menjadi contoh, teladan yang dapat diikuti oleh pustakawan lainnya Seperti yang disampaikan dalam Panduan Diseminasi Best Practice (Departemen Pendidikaan Nasional, 2008) sebaiknya Best Practice didiseminasikan kepada orang lain dengan berbagai strategi diberbagai tempat secara berulang-ulang sehingga dapat dicontoh dan diadopsi oleh orang lain.

\section{HASIL DAN PEMBAHASAN}

Perpustakaan Kementerian Kesehatan merupakan unit pembina perpustakaan dan pustakawan di lingkungan Kementerian Kesehatan yang tersebar di seluruh Indonesia. Perpustakaan di lingkungan Kementerian Kesehatan harus dikelola secara professonal oleh para pustakawannya berdasarkan sistem yang baku untuk mendukung kelancaran atau keberhasilan pencapaian visi, misi dan tujuan Kementerian Kesehatan. Sedangkan pustakawan adalah profesi yang memiliki kontribusi besar dalam mewujudkan cita-cita luhur bangsa Indonesia dalam mencerdaskan kehidupan bangsa (Kementerian Kesehatan, 2019)

Meskipun masih dalam jumlah terbatas, sebagian pustakawan di lingkungan Kementerian Kesehatan telah melakukan pelayanan yang terbaik sesuai dengan kemampuannya. Oleh karena itu sudah sepantasnya apabila para pustakawan yang berdedikasi tinggi, melakukan inovasi, serta turut berperan dalam meningkatkan derajat kesehatan masyarakat diberi apresiasi dan penghargaan. Salah satu bentuk apresiasi yang diberikan adalah melalui Pemilihan Pustakawan inovatif Terbaik.

Pelaksanaan Pemilihan Pustakawan inovatif Terbaik dilakukan melalui beberapa tahap. Tahap awal adalah penyusunan Term of Reference (TOR) kegiatan dan memasukkan butir kegiatan kedalam Rencana Kerja dan Anggaran Kementerian dan Lembaga (RKAKL). Kemudian menentukan tema kegiatan dan menyusun Pedoman Pemilihan Pustakawan Inovatif Terbaik yang berisi tentang persyaratan, penilaian, ketentuan dan kelengkapan dalam mengikuti Pemilihan Pustakawan Inovatif Terbaik. Selanjutnya menyusun Surat Keputusan (SK) 
Kepanitiaan Pemilihan Pustakawan Inovatif Terbaik di Lingkungan Kementerian Kesehatan yang anggotanya terdiri dari dewan juri, panitia pelaksana dan sekretariat. Tim juri berasal dari pakar dibidang perpustakaan, penggiat perpustakan dan pimpinan Perpustakaan Kementerian Kesehatan. Setelah itu secretariat membuat surat yang berisi informasi tentang Pemilihan Pustakawan Inovatif Terbaik dilengkapi dengan pedomannya dikirimkan ke seluruh satuan kerja (satker) di lingkungan Kementerian Kesehatan di seluruh Indonesia.

Langkah selanjutnya Kepala satker memilih calon peserta pemilihan melalui penyaringan mandiri dengan memperhatikan persyaratan calon peserta. Adapun persyaratannya sebagai berikut pengelola perpustakaan di lingkungan kementerian Kesehatan yang telah bekerja minimal satu tahun, berlatar belakang pendidikan ilmu perpustakaan sekurangnya D2 Ilmu Perpustakaan atau bidang lain di tambah diklat Calon Pustakawan Tingkat Trampil (CPTT) dan Calon Pustakawan Tingkat Ahli (CPTA). Memiliki prestasi kerja tahunan dengan hasil minimum "baik" dan menjadi anggota organisasi profesi pustakawan. Tidak sedang menduduki jabatan structural atau fungsional di luar bidang perpustakaan dan terakhir adalah peserta Pemilihan Pustakawan Inovatif Terbaik diusulkan secara tertulis oleh Kepala Satker tempat pustakawan bekerja (minimal Eeslon III).

Calon peserta pemilihan yang terpilih mandiri oleh Kepala Satker kemudian menyiapkan dokumen untuk mengikuti Pemilihan Pustakawan Inovatif Terbaik diantaranya satu makalah inovasi sesuai dengan tema yang telah ditentukan oleh panitia (minimal 10 halaman, 7.500 kata), rekomendasi kepala satker, deskripsi tugas (maksimal lima halaman, berisi tugas, tanggung jawab dan inovasi yang dilakukan) serta daftar riwayat hidup. Untuk makalah inovasi, format yang ditetapkan oleh panitia harus memenuhi ketentuan sebagai berikut:

Tabel 1. Format Makalah Inovasi

Pemilihan Pustakawan Inovatif Terbaik

\begin{tabular}{|l|l|c|}
\hline \multicolumn{1}{|c|}{ Format Penulisan } & \multicolumn{1}{|c|}{ Penjelasan } & Maksimum Kata \\
\hline Ringkasan & $\begin{array}{l}\text { Ringkasan dari inovasi } \\
\text { pelayanan perpustakaan } \\
\text { yang diajukan }\end{array}$ & \\
\hline Analisis Masalah & $\begin{array}{l}\text { Masalah yang dihadapi } \\
\text { sebelum inovasi } \\
\text { dilaksanakan. Uraikan fakta } \\
\text { dan situasi dengan didukung } \\
\text { data. Kelompok pemustaka } \\
\text { mana yang terpengaruh dan } \\
\text { masalah utama apa yang } \\
\text { perlu diselesaikan. }\end{array}$ & \\
\hline Pendekatan Strategis & $\begin{array}{l}\text { Ringkasan tentang apa dan } \\
\text { bagaimana inovasi } \\
\text { pelayanan perpustakaan ini } \\
\text { teah memecahkan masalah } \\
\text { dan uraikan strateginya. }\end{array}$ & \\
\hline Kreatif dan Inovatif & $\begin{array}{l}\text { Jelaskan tentang keunikan } \\
\text { inovasi pelayanan } \\
\text { perpustakaan, mampu } \\
\text { menyelesaikan masalah } \\
\text { dengan cara yang baru dan } \\
\text { berbeda dari metode } \\
\text { sebelumnya serta berhasil } \\
\text { diimplementasikan. }\end{array}$ & \\
\hline Pelaksanaa dan Penerapan & $\begin{array}{l}\text { Menguraikan unsur-unsur } \\
\text { rencana aksi yang telah }\end{array}$ & \\
\hline
\end{tabular}


Vol 2. No. 1, Januari 2022 P-ISSN : 2774-8030, e-ISSN : 2774-8030

\begin{tabular}{|c|c|c|}
\hline & $\begin{array}{l}\text { dikembangkan untuk } \\
\text { melaksanakan inovasi } \\
\text { pelayanan perpustakaan, } \\
\text { termasuk perkembangan dan } \\
\text { langkah-langkah kunci, } \\
\text { kegiatan utama beserta } \\
\text { kronologinya. }\end{array}$ & \\
\hline Pemangku Kepentingan & $\begin{array}{l}\text { Menyebutkan siapa saja } \\
\text { yang telah berkontribusi } \\
\text { untuk desain dana tau } \\
\text { pelaksanaan inovasi } \\
\text { pelayanan perpustakaan. }\end{array}$ & 400 \\
\hline Sumber Daya & $\begin{array}{l}\text { Menyebutkan sumber daya } \\
\text { yang terkait dengan inovasi } \\
\text { pelayanan perpustakaan } \\
\text { yaitu SDM, teknis dan } \\
\text { anggaran }\end{array}$ & 600 \\
\hline Keluaran/Output & $\begin{array}{l}\text { Menyebutkan paling banyak } \\
\text { lima keluaran konkret yang } \\
\text { mendukung keberhasilan } \\
\text { inovasi pelayanan } \\
\text { perpustakaan }\end{array}$ & 500 \\
\hline Manfaat & $\begin{array}{l}\text { Menguraikan dampak/ } \\
\text { manfaat dari inovasi } \\
\text { pelayanan perpustakaan } \\
\text { dengan memberikan } \\
\text { beberapa pembuktian/data }\end{array}$ & 800 \\
\hline Sebelum dan sesudah & $\begin{array}{l}\text { Menguraikan perbedaan } \\
\text { sebelum dan sesudah inovasi } \\
\text { pelayanan perpustakaan } \\
\text { dilakukan }\end{array}$ & 800 \\
\hline Keselarasan & $\begin{array}{l}\text { Apa saja dari kegiatan } \\
\text { inovasi tersebut yang sejalan } \\
\text { dengan satu atau lebih dari } \\
17 \text { tujuan Pembangunan } \\
\text { sesuai Rencana Strategis } \\
\text { (Renstra) Kementerian } \\
\text { Kesehatan. }\end{array}$ & 400 \\
\hline Pembelajaran & $\begin{array}{l}\text { Menguraikan pengalaman } \\
\text { umum yang diperoleh dalam } \\
\text { melaksanakan inovasi, } \\
\text { pembelajaran dan } \\
\text { rekomendasi untuk masa } \\
\text { depan. }\end{array}$ & 600 \\
\hline Kelanjutan dan Replikasi & $\begin{array}{l}\text { Menguraikan bagaimana } \\
\text { inovasi pelayanan } \\
\text { perpustakaan dilanjutkan } \\
\text { dan bagaimana inovasi } \\
\text { tersebut direplikasikan } \\
\text { (transfer of knowledge) }\end{array}$ & 600 \\
\hline
\end{tabular}


Selanjutkan semua dokumen calon peserta pemilihan Pemilihan Pustakawan Inovatif Terbaik dikirimkan ke sekretariat untuk diseleksi. Kemudian panitia melakukan seleksi berdasarkan semua dokumen yang dikirimkan oleh calon peserta. Panitia akan menganulir dan menolak calon peserta pemilihan bila ditemukan ketidaksesuaian kualifikasi dan persyaratan sesuai aturan yang telah ditetapkan oleh panitia. Bagi calon peserta yang memenuhi persyaratan maka sekretariat akan meneruskan makalah inovasinya kepada dewan juri untuk dinilai.

Dewan juri akan menilai makalah inovasi calon peserta pemilihan berdasarkan kriteria dan bobot penilaia sebagai berikut format penulisan (15\%), tata bahasa (15\%), alur penulisan (10\%), kesesuaian, keluasan, kedalaman, materi serta nilai (value) dari muatan tulisan bagi perkembangan perpustakaan internal, eksternal dan masyarakat (60\%). Dari semua makalah inovasi yang masuk kemudian dipilih 12 orang pustakawan calon peserta pemilihan yang memiliki nilai makalah inovasi terbaik. 12 orang pustakawan inilah nantinya yang akan menjadi nominasi untuk mengikuti uji presentasi dan wawancara oleh dewan juri. Hasil penilaian dan penentuan nominasi oleh dewan juri kemudian dibuatkan berita acara penilaian oleh secretariat yang kemudian ditandatangani dan disahkan oleh dewan juri.

Selanjutnya secretariat mengumumkan hasil penilaian dan menyampaikan nama-nama nominasi pemilihan pustakawan inovatif terbaik. Bagi pustakawan yang namanya terpilih menjadi nominator, maka secretariat memberitahukan tempat dan jadwal untuk mengikuti ujian selanjutnya. Para nominator diasramakan selama 3 hari dan 2 malam untuk mengikuti ujian presentasi dan wawancara. Pada pelaksanaan ujian peserta akan mempresentasikan makalah inovasi yang telah dibuat. Presentasi dilakukan dalam Bahasa Indonesia dihadapan dewan juri dan disaksikan oleh peserta lainnya. Lamanya presentasi minimal 15 menit dan tanya jawab 30 menit. Sedangkan aspek yang dinilai adalah pemahaman pada isi makalah, relevansi tayangan dengan isi makalah, kesesuaian alur paparan, ketepatan bahasa (lisan dan tulisan) serta daya tarik penampilan peserta. Secara keseluruhan bobot penilaian pelaksanaan ujian ini meliputi presentasi makalah (35\%), wawancara pendalaman materi makalah (35\%), penugasan penulisan (action plan) dengan bobot $20 \%$ dan peer review (10\%). Dari hasil ujian presentasi dan wawancara akhirnya terpilih Pustakawan Inovatif Terbaik 1 s/d 3 dan Harapan 1 s/d 3.

Tabel 2. Daftar pemilihan pustakawan inovatif terbaik

Di lingkungan kementerian kesehatan tahun 2019

\begin{tabular}{|c|c|c|c|c|}
\hline NO & NAMA & $\begin{array}{c}\text { UNIT } \\
\text { KERJA }\end{array}$ & JUDUL MAKALAH & KETERANGAN \\
\hline 1 & $\begin{array}{l}\text { Kartika Ida } \\
\text { Rahayu, } \\
\text { S.I.Pust }\end{array}$ & $\begin{array}{l}\text { Poltekes } \\
\text { Kemenkes } \\
\text { Semarang }\end{array}$ & $\begin{array}{l}\text { Pemberdayaan Masyarakat dalam } \\
\text { Pengolahan Limbah ampas Tahu } \\
\text { menjadi Nugget tahu di Desa Mersi } \\
\text { Purwokerto Timur Banyumas Jawa } \\
\text { Tengah }\end{array}$ & Terbaik 1 \\
\hline 2 & $\begin{array}{l}\text { Aziz } \\
\text { Alfarisy, } \\
\text { S.Hum }\end{array}$ & $\begin{array}{l}\text { RSUP } \\
\text { DR.Kariadi } \\
\text { Semarang }\end{array}$ & $\begin{array}{l}\text { Gerobag Buku "Baca Aku Dong" } \\
\text { (Layanan Sirkulasi untuk Pasien) }\end{array}$ & Terbaik 2 \\
\hline 3 & $\begin{array}{l}\text { Nadia } \\
\text { Amelia } \\
\text { Qurrota } \\
\text { Ayunin } \\
\text { S.Hum, MA }\end{array}$ & BPPSDM & $\begin{array}{l}\text { Strategi promosi Kesehatan } \\
\text { Pustakawan dalam meningkatkan } \\
\text { derajat kesehatan masyarakat } \\
\text { kampung Hang Jebat dan Lauser } \\
\text { Jakarta Selatan melalui pembinaan } \\
\text { PHBS dengan kegiatan story telling di } \\
\text { Perpustakaan BPPSDM Kesehatan }\end{array}$ & Terbaik 3 \\
\hline 4 & $\begin{array}{l}\text { Agus Yudo } \\
\text { Waluyo, } \\
\text { S.Sos }\end{array}$ & $\begin{array}{l}\text { Poltekkes } \\
\text { Bandung }\end{array}$ & $\begin{array}{l}\text { Website Perpustakaan sebagai transfer } \\
\text { Ilmu Pengetahuan }\end{array}$ & Harapan 1 \\
\hline
\end{tabular}


Vol 2. No. 1, Januari 2022 P-ISSN : 2774-8030, e-ISSN : 2774-8030

\begin{tabular}{|c|l|l|l|l|} 
& Aidatul & $\begin{array}{l}\text { RSUP. } \\
\text { Soeradji } \\
\text { Kirtonegoro } \\
\text { A.Md }\end{array}$ & $\begin{array}{l}\text { Peran PUSPA (Perpustakaan untuk } \\
\text { Pasien dan Keluarga) dalam } \\
\text { Keningkatkan Kualitas Hidup } \\
\text { Masyarakat di RSUP dr. Soeradji } \\
\text { Tirtonegoro Klaten }\end{array}$ & Harapan 2 \\
\hline 6 & $\begin{array}{l}\text { Rizqy } \\
\text { Hanida, } \\
\text { S.Hum }\end{array}$ & $\begin{array}{l}\text { Poltekkes } \\
\text { Surakarta }\end{array}$ & $\begin{array}{l}\text { Mengembangkan Perpustakaan } \\
\text { Menuju Learning Resource Center } \\
\text { (LRC) }\end{array}$ & Harapan 3 \\
\hline
\end{tabular}

Kemudian hasil pemilihan Pustakawan Inovatif Terbaik 1 s/d 3 dan Harapan 1 s/d 3 dituangkan dalam bentuk berita acara yang ditandatangani oleh Dewan Juri, disyahkan oleh pimpinan Biro Komunikasi dan Pelayanan Masyarakat sebagi instansi pembina yang menaungi Perpustakaan Kementerian Kesehatan dan ditetapkan oleh Menteri Kesehatan RI. Para pemenang pemilihan Pustakawan Inovatif Terbaik diundang ke Jakarta dan diberikan penghargaan dan hadiah di acara Malam Penghargaan Publikasi dan Pelayanan Publik Kementerian Kesehatan. Malam pernghargaan diselenggarakan untuk memberikan penghargaan bagi individu, organisasi maupun instansi yang berprestasi dalam bidang publikasi dan pelayanan publik termasuk pustakawan inovatif terbaik di lingkungan Kementerian Kesehatan. Acara bergengsi yang dihadiri oleh para pejabat negara diantaranya Menteri Kesehatan RI, Menteri Pendayagunaan Aparatur Negara dan Reformasi Birokrasi (MenpanRB), Kepala Perpustakaan Nasional, Kepala Ombudsman, Ketua Komisi Informasi Pusat (KIP) serta pejabat eselon 1 dan 2 Kementerian dan Lembaga terkait.

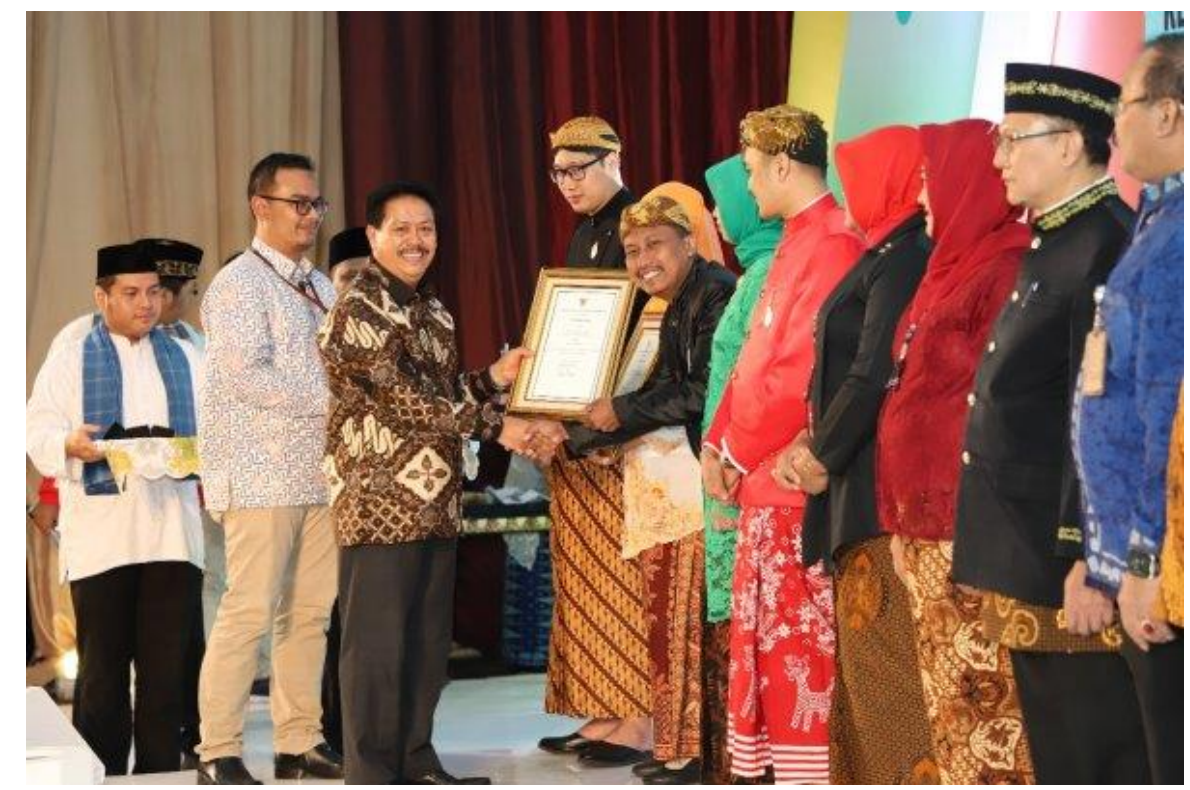

Gambar 1. Kepala Perpustakaan Nasional menyerahkan piagam penghargaan kepada Pustakawan Inovatif Terbaik di lingkungan Kementerian Kesehatan pada Malam Penghargaan Publikasi dan Pelayanan Publik Kementerian Kesehatan

(Jakarta, 21/8/2019)

Sumber foto: perpusnas.go.id

Kegiatan Pemilihan Pustakawan Inovatif Terbaik tidak berhenti sampai pemberian penghargaan. Makalah inovasi dan rencana kegiatan (plan of action) dari peserta pemilihan pustakawan inovatif diteruskan kepada Kepala Satker masing-masing untuk dimonitor dan dievaluasi implementasinya. Makalah inovasi para pustakawan diimplementasikan sesuai dengan plan of action yang telah disusun pustakawan berdasarkan rencana kegiatan jangka pendek, menengah, dan panjang. 
Dampak perubahan dari kegiatan Pemilihan Pustakawan Inovatif Terbaik adalah meningkatkan daya kritis pustakawan di lingkungan Kementerian Kesehatan terhadap permasalahan perpustakaan dan mampu memberikan sesuatu yang produktif. Menjadi insan yang solutif dan bermanfaat bagi perpustakaan dan kepustakawanan. Memiliki daya kompetitif dan hasrat untuk memperbaiki diri agar menjadi pustakawan yang lebih baik lagi, percaya diri, berkualitas dan siap bersaing dengan profesi lainnya.

\section{KESIMPULAN}

Pustakawan menjadi kunci utama keberlangsungan dan keberhasilan sebuah perpustakaan. Pustakawan juga merupakan profesi yang memiliki kontribusi besar dalam mewujudkan cita-cita luhur bangsa Indonesia dalam mencerdaskan kehidupan bangsa. Untuk itu kompetensi pustakawan perpustakaan perlu ditingkatkan dalam rangka mempersiapkan diri menjawab tantangan global dan persaingan di masa depan. Pemilihan Pustakawan Inovatif Terbaik merupakan suatu Best Practice dalam rangka meningkatkan kinerja dan inovasi dalam rangka optimalisasi pengembangan SDM perpustakaan yang berkualitas dan menjadi contoh teladan yang dapat diikuti oleh pustakawan maupun profesi lainnya.

\section{DAFTAR PUSTAKA}

Boven, K, Morohashi, J, \& Quick, R.E (2002). Best Prattice using Indigeneous Knowledge.

Dastina, W., \& Hikmat, A. N. (2018). Bentuk Pembinaan Karir Pustakawan Di Dinas Perpustakaan Dan Arsip Daerah Provinsi Jambi. Baitul'Ulum: Jurnal Ilmu Perpustakaan dan Informasi, 1-16

Fatmawati, E. (2016). Merajut inovasi pustakawan perguruan tinggi untuk mewujudkan SDM perpustakaan berkualitas. Pustakaloka, 8(2), 273-282.

Nashihuddin, W., \& Aulianto, D. R. (2015). Strategi peningkatan kompetensi dan profesionalisme pustakawan di Perpustakaan Khusus. Jurnal Perpustakaan Pertanian, 24(2), 51-58.

Panduan Diseminasi Best Practice, Direktorat Pembinaan Diklat, Ditjen Peningkatan Mutu Pendidikan dan Tenaga Pendidikan, Departemen Pendidikan Nasional, 2008.

Pedoman Pemilihan Pustakawan Inovatif Terbaik, Kementerian Kesehatan, 2019

Permenkes No. 38 Tahun 2015 tentang Penerbitan dan Serah simpan Karya cetak dan Karya Rekam di Lingkungan Kementerian Kesehatan.

Permenkes No. 58 Tahun 2015 tentang Pedoman Penyelenggaraan Perpustakaan di Lingkungan Kementerian Kesehatan.

Sudarsono, B. (2020). Pustakawan dan Perpustakaan dalam menghadapi tantangan di Era Global. Media Pustakawan, 18(3), 1-8.

UU no. 43 Tahun 2007 tentang Perpustakaan 